\title{
Implications of Climate Change Impacts on Regional Maize Production in the United States: Risk Mitigation Strategies and Food Security
}

\author{
Xiang Li and Nobuhiro Suzuki
}

\begin{abstract}
Analyzing the impacts of climate change on regional maize production in the North Central and the South regions of the United States and proposing risk mitigation strategies have significant implications in the context of national and global food security. Unlike most estimation, we use an interdisciplinary approach and combine climatic variables along with economic inputs and technological improvement in the adapted Cobb-Douglas production function model. The production function is simulated through 2030 under a variety of climate change scenarios, and the results indicate that under the climate change South region tends to have opposite impacts relative to the North Central, the major maize production region in the United States. The results imply that one region's losses can be partially offset by the other region's gains. The different responses imply that the South region could provide potential risk mitigation to climate change within the United States and could help the nation and the world maintain maize supply stability. The results gained from this research could be used as cost-efficient climate change risk mitigation strategies for other agricultural commodities in other countries. They can also be used for public policies and advanced risk mitigation and diversification programs, and are expected to contribute to the sustainability of agriculture and the stability of international crop market price in the United States and the world.
\end{abstract}

Index Terms-Climate change, cost-efficient climate change risk mitigation strategies, food security, sustainability of agriculture.

\section{INTRODUCTION}

It has become increasingly clear among scientists that a continuous increase in atmospheric greenhouse emissions is changing the climate of the earth [1]-[9]. Global general circulation models (GCMs), which are our best tools for predicting future climates, indicate that the earth's surface temperature could rise by an average of $1.5^{\circ} \mathrm{C}$ to $4.5^{\circ} \mathrm{C}$ over the next 50 to 100 years due to increasing concentrations of greenhouse gases in the atmosphere [4]. These models also predict an increase in average global precipitation, but there is less agreement among GCMs as to the potential distribution of precipitation changes. Any change in climate will have implications for climate-sensitive systems such as forestry, other natural resources, and agriculture.

In the agricultural sector, changes in climatic variables will

Manuscript received May 1, 2013; revised June 15, 2013.

Xiang Li is with Tokyo Institute of Technology, Tokyo, 152-8550 Japan (e-mail: li.x.ao@m.titech.ac.jp).

Nobuhiro Suzuki is with the University of Tokyo, Japan (e-mail: asuzukiz@mail.ecc.u-tokyo.ac.jp). cause agronomic effects such as changes in crop yields. Climate change will also produce a host of economic effects pertaining to agriculture, including changes in farm profitability, prices, supply, demand, trade, and regional comparative advantage. The agronomic and economic impacts of climate change will depend principally on two factors: (1) the magnitudes of changes in climatic variables, and (2) how well agriculture can adapt to these changes. Given the backdrop that maize is a major food crop and a valuable renewable energy bioethanol, we focus on the potential impacts of climate change on regional maize production in the United States in this paper.

The United States is the largest producer of maize in the world and accounts for over one-third of the world market share in terms of exports. Most of the maize produced in the United States is grown in the "Corn Belt", which includes states in the North Central region of the country (Fig.1). The South region is a much smaller producer of national output, but is included in the analysis since it may experience different impacts of climate change relative to the North Central region.
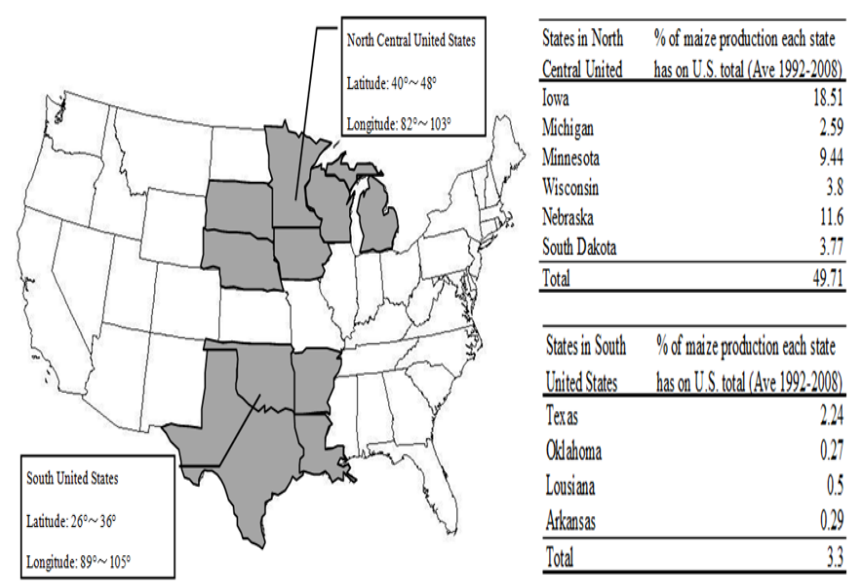

Fig. 1. Geographic range of maize production in North Central and South United States

Within a large country like the United States, different climatic and socioeconomic conditions in the North Central and the South regions could imply different regional impacts of climate change on crop production. These regions include the six major maize producing states in the North Central region (Iowa, Michigan, Minnesota, Wisconsin, South Dakota, and Nebraska), which range from $40^{\circ}$ to $48^{\circ}$ north by latitude, $82^{\circ}$ to $103^{\circ}$ west by longitude, and the four major maize producing states in the South region (Texas, Louisiana, Oklahoma, Arkansas), which range from $26^{\circ}$ to $36^{\circ}$ north by 
latitude, $89^{\circ}$ to $105^{\circ}$ west by longitude. The North Central region accounts for $50 \%$ of total maize production amount in the nation (Fig.1). Although its share of maize production accounts for only $3 \%$ of total national maize production, the South region's potential for auxiliary maize production to offset or even to outweigh the potential climate change-induced reductions of maize production in the North Central region could be significant.

Previous climate change impact studies have used either biophysical crop simulation models such as CERES-maize and EPIC models, statistical yield models, or mathematical programming methods to analyze the impacts of climate change on maize production [10]-[18]. Unlike most production function estimations, we use a multidisciplinary approach in this study and combine climatic variables along with economic inputs and technological improvement in the function to estimate the impact of climate change on maize production in the two regions of the United States. The potential differences in regional responses of maize production to climate change provide useful information on how the United States may adapt to climate change through shifts in regional production. The adapted production function is simulated through 2030 under a variety of climate change scenarios, and the results indicate that under the climate change South region tends to have opposite impacts relative to the North Central region, implying that one region's losses can be partially offset by the other region's gains. Such a different response implies that the South region could provide potential risk mitigation to climate change within the United States and could help the nation and the world maintain maize production balance.

\section{MAterials AND Methodology}

Climate inputs, production inputs, and technology are combined in an adapted Cobb-Douglas production function to analyze the impacts of climate change on maize production in North Central and South regions. The structure of the model is highlighted conceptually in Fig. 2, which shows the relationships among the variables. Temperature and precipitation link to the growth and final outputs of maize, and correspond to the sensitive dates in the development of maize. In this research, the " $\mathrm{CO}_{2}$ fertilizer effect" is not assumed to have any effects on maize yields, as the interaction of $\mathrm{CO}_{2}$ with other environmental factors is still debatable among scientists [4], [5], [11], [19].

For both regions, the following equation is used

$$
\begin{gathered}
\ln (Y)=\beta_{0}+\beta_{1} \ln (A)+\beta_{2} \ln (L)+\beta_{3} \ln (M A)+\beta_{4} \ln (C F) \\
+\beta_{5} \text { TECH+ } \beta_{6} W T E M P+\beta_{7} W_{T E M P^{2}} \\
+\beta_{8} W P R E+\beta_{9} W_{P R E^{2}}
\end{gathered}
$$

where $Y$ is the estimated maize production output (bushels); $\beta_{0} \beta_{9}$ are estimated coefficients; $A$ is land use (in dollars); $L$ represents labor that contributes to the production of maize (in dollars); $M A$ is agricultural machinery use (in dollars); $C F$ refers to the chemical fertilizer use (in dollars); $T E C H$ is technology (linear trend term); WTEMP is weighted temperature and WPRE is weighted precipitation where temperature and precipitation in the key planting stage and climate sensitive growing stage of maize (vegetative stage and reproductive stage) are equally weighted separately in (1) to reflect their importance to maize (see Table I).

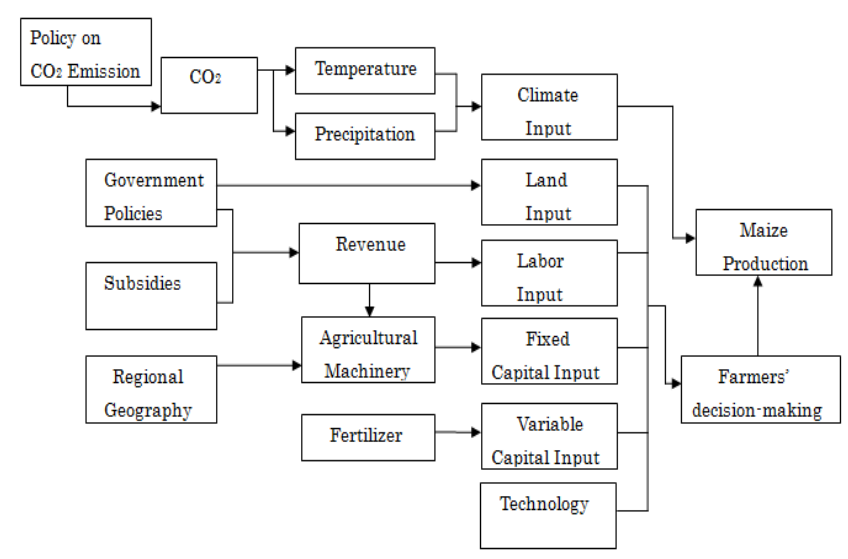

Fig. 2. Model structure of this research

TABLE I: MONTHS CORRESPOND TO THE TEMPERATURE AND

\begin{tabular}{|c|c|c|}
\hline Stages & North Central & South \\
\hline Planting and seedling & April, May & April, May \\
\hline Growing (Vegetative) & June & June \\
\hline Growing (Reproductive) & July & July \\
\hline
\end{tabular}
Precipitation Sensitive Stages of MaIze Crop In THE NoRTH Central AND THE SOUTH UNITED STATES

States that are classified to be the same climate division and correspond to the major maize producing sites are grouped into the same region [20], [21]. For estimation in (1), cross-sectional and time series data from the 10 major maize producing states in the two regions over the time period 1992 to 2008 are used. In the United States, each state is composed of 8 to 10 districts under the climate division of NOAA. Cross sectional and time series data on average monthly temperature and average monthly accumulated precipitation that correspond to the planting stage and the key growing stage of maize are collected at the district levels, and then pooled and averaged for each state.

To correct for any quality difference in inputs between the two regions, all production inputs in (1) expressed in dollar terms are deflated by price paid index [22]. States that have similar maize production practices were categorized to be the same region prior to 1995. Data in each state prior to 1995 are collected from the earlier defined regions (North Central; Plain States; Southeast). Thereafter, classification of ERS Farm Resource regions becomes a dominant method to better reflect the regional differences in farm types within the country [23]. Thus, data thereafter are collected from the updated version of farm region classification system (Heartland; Northern Crescent; Northern Great Plains; Prairie Gateway; Southern Seaboard; Eastern Uplands).

Under the definition of USDA Commodity Costs and Return, the importance of land production input is reflected as land rental costs. Thus, data on lands are first collected from the USDA, then converted to the state-level total land costs, and deflated [5], [23].

Labor is composed of two parts: hired labor and unpaid labor. While the self-employment belongs to the category of 
unpaid labor where the opportunity costs of providing unsalaried labor are measured, costs of hiring people for maize production are categorized as hired labor [22]. The two types of labor costs at state levels are then summed, converted to the total labor costs and deflated.

Capital costs incurred during the process of maize production are defined differently before and after 1995. Prior to 1995, capital costs were defined to be the sum of capital replacement costs and nonland capital costs [23]. While the capital replacement costs were a part of machinery and equipment value, of which the repairs must be paid during the maize production process to maintain the production operation, nonland capital costs were the opportunity costs of investments on farm machinery and equipments that reflect the effective use of capital resources in the production process. To further improve the measuring quality of actual capital costs incurred during the process of maize production, the data switched to the AAEA task force recommendations in 1996, and capital recovery method replaced the previous capital replacement and nonland capital. Thus, two types of capital cost data prior to 1995 are collected from the U.S. commodity Costs and Return data sector and summed up. The processed data prior to 1995 and capital cost data defined by the updated system since 1996 are converted to the state-level total capital costs and deflated [23].

Similar to the processing method of land input, data on fertilizer costs that account for the major share of total maize production costs and available at the state levels are also collected based on the different production region classifications prior to and after 1995, then converted to total fertilizer costs and deflated.

In addition to climate inputs and production inputs, technology improvement input is also included in the equation to reflect the reality of its importance to maize production under climate change. In this research, technology improvement over the estimated period is assumed to change at a stable rate. It is expressed as a linear time trend as a proxy of technology improvement over time in (1).

\section{RESULTS}

\section{A. Analysis}

The contribution of each climatic, production input, and technology in influencing maize outputs in both regions is analyzed at first based on the estimated function (see Table II). The results indicate that maize production responds differently to climate and maize production inputs in the two regions. For both regions, the planting season is between April and May, but a warmer climate in the lower latitude South region enables farmers to start maize planting earlier (Table I, [23]).

The estimated production functions indicate that among production inputs, land has the largest effect on maize production in both regions (see Table II). A $1 \%$ increase in land is found to increase maize outputs by $0.49 \%$ in the North Central region and by $0.36 \%$ in the South region, holding all other factors constant. The higher elasticity for the North
Central region indicates that its land yields higher output levels for maize than the South region.

Despite the fact that agricultural machinery is critically important for U.S. crop production, labor is still an important input to maize production in the United States. While the labor input in the North Central has the second largest effect on maize production, where a $1 \%$ increase in the labor input leads to a $0.32 \%$ increase in maize production, the labor input in the South region is only one-third as large, where a $1 \%$ increase in the labor input leads to a $0.11 \%$ increase in maize production, holding all other inputs constant. In the North Central region, there has been a positive trend in self-employment labor and a decrease in hired labor over time, which has been due to a decrease in hired labor availability. The larger labor input elasticity in the North Central is likely the result of the relative regional scarcity of hired labor in the North Central region. In contrast, the availability of hired labor in the South region is more abundant and less expensive.

Machinery is also an important input for maize production. A $1 \%$ increase in the machinery input is estimated to increase maize production by $0.25 \%$ in the North Central region and $0.21 \%$ in the South region, holding all other factors constant.

Despite the key role of the fertilizer input to maize production in the United States, its contribution to maize production is smaller in the North Central region, but is the second largest among production inputs to maize production in the South region. A $1 \%$ increase in fertilizer input is found to increase maize production by $0.18 \%$ in the North Central and $0.35 \%$ in the South, holding all other factors constant. The results are consistent with the regional differences in soil nutrient contents and qualities.

TABLE II: MODELING RESUltS IN THE NORTH CENTRAL AND SOUTH OF THE UNITED STATES (DATA OVER 1992-2008 ARE UTILIZED)

\begin{tabular}{|c|c|c|}
\hline $\begin{array}{l}\text { Explained variable, } \ln \text { (maize } \\
\text { outputs) }\end{array}$ & $\begin{array}{l}\text { North Central } \\
\text { region }\end{array}$ & South region \\
\hline Explanatory variables & $\begin{array}{l}\text { Coefficient } \\
\text { (t-values) }\end{array}$ & $\begin{array}{l}\text { Coefficient } \\
\text { (t-values) }\end{array}$ \\
\hline Constant & $-47.99(-4.50)$ & $-33.17(-3.59)$ \\
\hline $\ln (A)$ & $0.49(6.20)$ & $0.36(5.18)$ \\
\hline $\ln (L)$ & $0.32(2.86)$ & $0.11(1.31)$ \\
\hline $\ln (M A)$ & $0.25(3.10)$ & $0.21(2.05)$ \\
\hline $\ln (C F)$ & $0.18(2.83)$ & $0.35(4.04)$ \\
\hline TECH & $0.02(4.50)$ & $0.02(3.66)$ \\
\hline WTEMP & $0.27(1.45)$ & $0.63(1.51)$ \\
\hline $\mathrm{WTEMP}{ }^{2}$ & $-0.01(-1.33)$ & $-0.01(-1.50)$ \\
\hline WPRE & $0.01(3.74)$ & $0.01(3.12)$ \\
\hline $\mathrm{WPRE} E^{2}$ & $-6.89 \cdot 10^{-5}(-4.38)$ & $-3.38 \cdot 10^{-5}(-2.42)$ \\
\hline R squared & 0.96 & 0.98 \\
\hline Adjusted R squared & 0.96 & 0.98 \\
\hline D.W. & 1.37 & 1.55 \\
\hline
\end{tabular}

Over the years, the United States has invested in crop research and development. Though the contribution of technology improvement factor to maize production is inelastic, a positive impact is observed. Specifically, a $1 \%$ increase in technology is found to increase maize outputs by $2 \%$ in both regions, holding all other factors constant. 
The climate inputs are found to have opposite effects on maize production in the two regions. In the North Central region, average temperature over the analysis period at the current 2008 level (average of three years' temperature from 2006 to 2008 is $16.05^{\circ} \mathrm{C}$ ) is below the peak average temperature $\left(16.91^{\circ} \mathrm{C}\right)$, holding all other factors constant. A $1{ }^{\circ} \mathrm{C}$ increase in temperature from the current level is found to increase maize production by $0.58 \%$ from the present, but is below the maize production level at the peak temperature. In the South region, average temperature at the current level (average of three years' temperature from 2006 to 2008 is $23.26^{\circ} \mathrm{C}$ ) is slightly over the turning point of average temperature $\left(23.1^{\circ} \mathrm{C}\right)$. A $1^{\circ} \mathrm{C}$ increase in temperature above the current level is found to decrease maize $1.77 \%$ from the 2008 level. A positive response to temperature in the North Central region is likely due to its higher latitude range and relatively lower temperature.

On the other hand, average precipitation over the analysis period in the North Central region at the current level (average of three years' precipitation from 2006 to 2008 is $87.93 \mathrm{~mm}$ ) is slightly below the turning point of average precipitation $(89.9 \mathrm{~mm})$, holding that all other factors are constant. Though a $1 \mathrm{~mm}$ increase in precipitation can increase maize outputs by $0.02 \%$ from the present level, a further increase in precipitation can have negative impacts on maize production. This result is consistent with an earlier report that showed precipitation change derived by climate change can decrease maize production [1], [14], [24]. In the South region, average precipitation over the analysis period at the current level (average of three years' precipitation from 2006 to 2008 is $104 \mathrm{~mm}$ ) is well below the peak turning point $(145.87 \mathrm{~mm})$, holding all other factors constant. A $1 \mathrm{~mm}$ increase in precipitation is found to increase maize by $0.28 \%$. This more positive response in the South region is likely the result of the mitigating effects of a relatively warmer climate.

\section{B. Simulation}

To examine the potential effects of climate change on regional maize outputs in the United States five climate scenarios are simulated: (1) optimistic, or no climate change from 2008 level, (2) moderately warmer $\left(0.72^{\circ} \mathrm{C}\right)$ and wetter (5\% increase in precipitation), (3) moderately warmer $\left(0.72{ }^{\circ} \mathrm{C}\right)$ and drier $(5 \%$ decrease in precipitation), (4) extremely warmer $\left(1.32 \mathrm{C}^{\circ}\right)$ and wetter $(30 \%$ increase in precipitation), and (5) extremely warmer $\left(1.32 \mathrm{C}^{\circ}\right)$ and drier (30\% decrease in precipitation). These scenarios are based on the projected changes specified in the Fourth Assessment Report of the Intergovernmental Panel of Climate Change (Table III, [4]). Since the consensus on future projecting directions of precipitation has not been established, two patterns of precipitation were simulated for each of changed temperature scenarios. Given the fact the United States is a leading country in research and development, its technological progress has been steadily increasing for decades, future trend on technology improvement over the simulating period is assumed to follow that estimated with the historical data used in the estimation. The impacts of climate change on maize production are analyzed over the period 2009-2030.

Fig. 3 displays simulated maize outputs in the North
Central region through 2030 for the five climate scenarios. With technology improvement following past trends, maize production is predicted to increase from just over one billion bushels (2008) to 1.72 billion bushels (2030) under no climate change. This represents a $71 \%$ increase due to technological improvement when no change in climate is assumed. Under all climate change scenarios, maize production increases over time but at different rates. For example, under both moderate scenarios, maize production actually increases by more than under no climate change. Specifically, by 2030, maize production in the moderately warmer scenarios is $0.6 \%$ (wetter) higher and $0.3 \%$ (drier) higher than under no climate change. However, maize production suffers slightly under the more extreme scenarios compared with no climate change. For example, under the extreme drier scenario, maize production is about $5 \%$ lower by 2030 compared with the no climate change scenario.

TABLE III: PROJECTED TEMPERATURE INCREASE SCENARIOS CORRESPONDING TO ATMOSPHERIC $\mathrm{CO}_{2}$ CONCENTRATION LEVELS SPECIFIED BY THE IPCC OVER THE PERIOD 2009-2030 [4]

\begin{tabular}{lll} 
Scenarios & $\begin{array}{l}\mathrm{CO}_{2} \text { concentration levels in } \\
\mathrm{ppm} \text { (IPCC scenario) }\end{array}$ & $\begin{array}{l}\text { Temperature } \\
\text { variation }\left({ }^{\circ} \mathrm{C}\right)\end{array}$ \\
\hline $\begin{array}{l}\text { no change from the } \\
\text { 2008 level }\end{array}$ & 368 (IPCC A1 scenario) & $\begin{array}{l}\text { No change from the } \\
2008 \text { level } \\
\text { Mild change }\end{array}$ \\
$\begin{array}{l}\text { Moderate change } \\
\text { pessimistic and } \\
\text { extreme change }\end{array}$ & 420 (IPCC A2 scenario) & $0.32^{\circ} \mathrm{C}$ \\
\hline
\end{tabular}
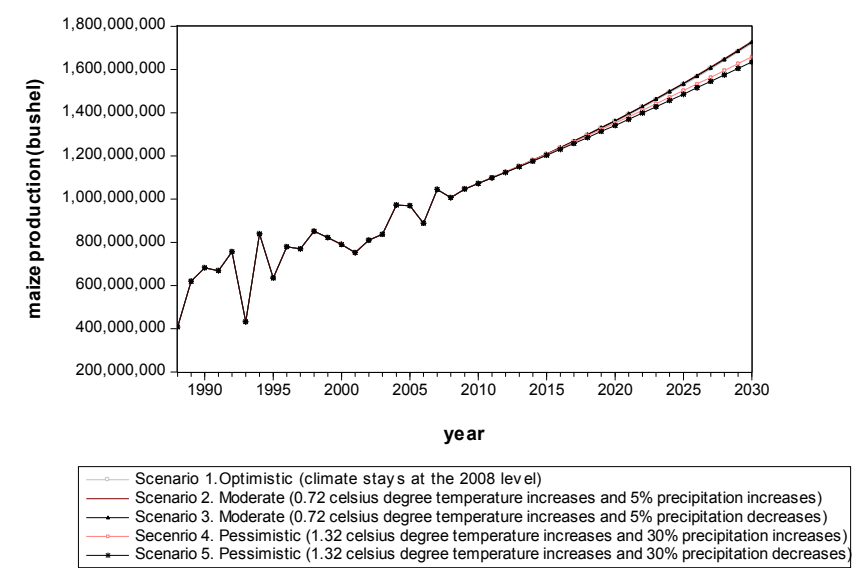

Fig. 3. Five simulated scenarios of maize outputs in the North Central United Stated over the period 2009 to 2030

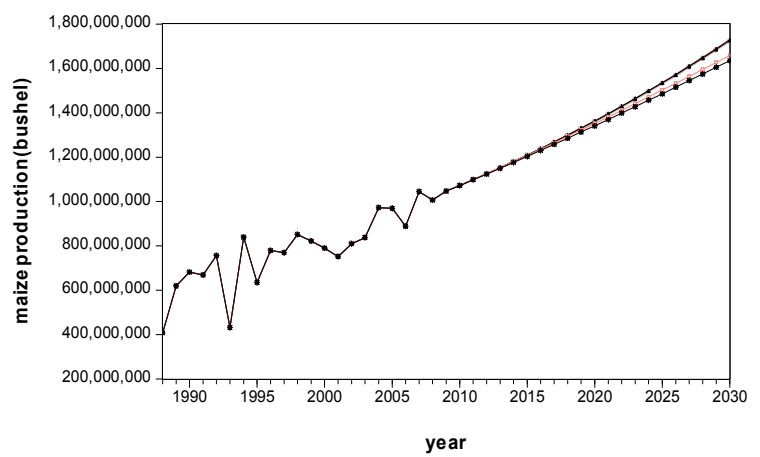

Scenario 1. Optimistic (climate stays at the 2008 level) Scenario 2. Moderate ( 0.72 celsius degree temperature increases and $5 \%$ precipitation increases) Scenario 3. Moderate ( 0.72 celsius degree temperature increases and $5 \%$ precipitation decreases $)$ Secenrio 4. Pessimistic (1.32 celsius degree temperature increases and $30 \%$ precipitation increases
Scenario 5. Pessimistic (1.32 celsius degree temperature increases and $30 \%$ precipitation decreases

Fig. 4. Five simulated scenarios of maize outputs in the South United Stated over the period 2009 to 2030 
In the South region, maize production increases from 107.7 million bushels in 2008 to 166.1 million bushels in 2030 in the no climate change scenario (Fig.4). That is, technological progress causes an increase of $54.2 \%$ in maize output assuming climate does not change. As is true for the North Central region, maize production is higher under all climate change scenarios in 2030 compared to 2008 due to technological improvement. Located in the lower latitude, the South region has a higher average annual temperature $\left(17.32^{\circ} \mathrm{C}\right)$ than North Central region $\left(6.71^{\circ} \mathrm{C}\right)$. The evaporation rate of soil water in this region is faster during the growing period of maize. While an increase in precipitation mitigates the water deficiency of maize, a decrease in precipitation, even in the moderate scenario, puts pressure on maize. In comparison with the result in the no climate change scenario, maize output decreases by $2.5 \%$ and $14 \%$ in the moderate and severe scenarios, respectively, where precipitation decreases. However, maize production in this region is higher than under the no climate change scenario for the two scenarios involving an increase in precipitation. In the moderate and severe scenarios where precipitation increases, maize output by 2030 is $0.3 \%$ and $2.7 \%$ higher than the corresponding no climate change scenario. Hence, it appears that a warmer but wetter climate will increase maize production, while a warmer, but drier climate will decrease maize production relative to no climate change in the South region.

\section{Discussion}

The estimated results in this study indicate maize production will respond differently to the same climate change scenario within a country. Within a large country like the United States, regional differences in climatic, geographic, and socioeconomic conditions could differentiate the results of climate change on maize production. Analyses without the consideration of these perspectives could distort the understandings of climate change on maize production. Previous studies that analyzed the effects of climate change on maize production with regression models have mainly focused on the climatic impact perspectives. While Lobell and Burke [17] showed lower R squared values that ranges from 0.54 to 0.76 , Schlenker and Roberts [25] presented the results that the whole-country crop reduction could be high, ranging from $44 \%$ to $79 \%$. However; in reality, economic and technology improvement factors in addition to climatic factors simultaneously affect maize production. Our research that incorporates these key inputs into the model in contrast showed high squared values in both regions: 0.96 in the North Central and 0.98 in the South.

Our results found that when there is a $30 \%$ increase in precipitation accompanying the extreme climate change scenario, maize production by 2030 could increase by $64.77 \%$ (the North Central) and 58.44\% (the South) with the consideration of further technology improvements.

Our results also indicate that in one of the extreme scenarios, the benefits of climate change in improving maize production in the South region could partially mitigate some of the losses in the North Central region. That is, under the extreme scenario where precipitation increases by $30 \%$ and temperature increases by $1.32^{\circ} \mathrm{C}$, maize production in 2030 in the North Central falls $4 \%$ below the optimistic no climate change scenario. However, in this same scenario, maize production in the South region increases by $2.7 \%$ above the no climate change scenario.

\section{CONCLUSION}

Regional climatic, geographic and economic conditions make the responses of maize production different in the two regions. The differences in regional responses indicate that the South could be an important crop producing region for the United States to attain its national crop production (food security) target of risk mitigation and diversification.

Though the current share of maize production is the South is relatively smaller compared to the North Central, its relative opposite responses to climate change from the North Central presents a potential cost-efficient risk mitigation and diversification solution for national and even global food security and adaption strategy to climate change. By distributing the maize production to different regions instead of a concentrated, clustered style, the overall risk of having a large national crop loss could be mitigated and diversified. Thus, a further spatial distribution of crop production could be an essential step for the United States towards sustainable agricultural development and the stability of international crop market price.

The results gained from this research can be used for national policies and advanced risk mitigation programs. Needless to say, a further improvement in technology and investments on research and development are important for the sustainability of agricultural sector in a long-term perspective.

\section{REFERENCES}

[1] R. A. Brown and N. Rosenberg, "Climate change impacts on the potential productivity of corn and winter wheat in their primary United States growing regions," Climate Change, vol. 41, pp. 73-107, January 1999.

[2] C. Esteve, E. Manuel, and B. Katrina, "Reducing greenhouse gas emissions from deforestation and forest degradation in developing countries: revising the assumptions," Climate Change, vol. 100, pp. 355-388, January 2010.

[3] C. H. Gabriele and C. Ulrich, "Greenhouse gas induced climate change," Environmental Science and Pollution Research, vol. 3, pp. 99-102, June 1996.

[4] IPCC, "Summary for Policymakers. In: Climate Change 2007: Mitigation. Contribution of Working Group III to the Fourth Assessment Report of the Intergovernmental Panel on Climate Change [B. Metz, O. R. Davidson, P. R. Bosch, R. Dave, L. A. Meyer (eds)]," Cambridge University Press, 2007.

[5] X. Li, T. Takahashi, N. Suzuki, and H. M. Kaiser, "The impacts of climate change maize yields in the United States and China," Agricultural Systems, vol. 104, pp. 348-353, April 2011.

[6] H. Paeth, A. Hense, R. Glowienka-Hense, S. Voss, and U. Cubasch, "The North Atlantic Oscillation as an indicator for greenhouse-gas induced regional climate change," Climate Dynamics, vol. 15, pp. 953-960, December 1999.

[7] C. O. Stockle, P. T. Dyke, J. R. Williams, C. A. Jones, and N. J. Rosenberg, "A method for estimating the direct and climatic effects of rising atmospheric carbon dioxide on growth and yield of crops: part II-sensitivity analysis at three sites in the Midwestern USA," Agricultural Systems, vol. 38, pp. 239-256, 1992.

[8] F. N. Tubiello, C. Rosenzweig, R. A. Goldberg, S. Jagtap, J. W. Jones, "Effects of climate change on US crop production: simulation results using two difference GCM scenarios. Part I: Wheat, potato, maize, and 
citrus," Climate research, vol. 20, pp. 259-270, April 2002.

[9] T. M. L. Wigley, R. Richels, and J. A. Edmonds, "Economic and environmental choices in the stabilization of atmospheric $\mathrm{CO}_{2}$ concentration," Nature, vol. 379, pp. 240-243, January 1996.

[10] S. Kane, J. Reilly, and R. Bucklin, "Implications of the Greenhouse Effects for World Agricultural Commodity Markets," A U.S. Department of Agriculture paper presented at the Western Economic Association Conference, Lake Tahoe, 1989.

[11] H. M. Kaiser, S. J. Riha, D. S. Wilks, D. G. Rossiter, and R. Sampath, "A farm-level analysis of economic and agronomic impacts of gradual climate warming," American Agricultural Economics Association, vol. 75, pp. 387-398, May 1993.

[12] R. Mendelsohn, W. D. Nordhaus, and D. Shaw, "The Impact of Global Warming on Agriculture: A Ricardian Analysis," The American Economic Review, vol. 84, pp. 753-771, September 1994.

[13] D. L. Phillips, J. J. Lee, and R. F. Dodson, "Sensitivity of the US corn belt to climate change and elevated CO2: I. Corn and soybean yields," Agricultural Systems, vol. 52, pp. 481-502, December 1996.

[14] C. Rosenzweig, F. N. Tubiello, R. Goldberg, E. Mills, J. Bloomfield, "Increased crop damage in the US from excess precipitation under climate change," Global Environmental Change, vol. 12, pp. 197-202, October 2002.

[15] G. Tan and R. Shibasaki, "Global estimation of crop productivity and the impacts of global warming by GIS and EPIC integration," Ecological Modelling, vol. 168, pp. 357-370, October 2003.

[16] C. C. Chen, B. A. McCarl, and D. E. Schimmelpfennig, "Yield variability as influenced by climate: a statistical investigation," Climate Change, vol. 66, pp. 239-261, September 2004.

[17] D. B. Lobell and M. B. Burke, "On the use of statistical models to predict crop yield responses to climate change," Agricultural and Forest Meteorology, vol. 150, pp. 1443-1452, July 2010.

[18] Z. J. Yuan, "Analysis of agricultural input-output based on Cobb-Douglas production function in Hebei Province, North China," North China. African Journal of Microbiology Research, vol. 5, pp. 5916-5922, December 2011.

[19] H. M. Kaiser and P. Crosson, "Implications of climate change for US agriculture," American Journal of Agricultural Economics, vol. 77, pp. 734-740, August 1995.

[20] EIA. (2012). U.S. Climate Zones for 2003 CBECS: Consumption and Efficiency. U.S. Energy Information Administration. [Online]. Available: http://www.eia.gov/emeu/cbecs/climate_zones.html

[21] NOAA. (2012). U.S. Climate Regions national Oceanic and Atmospheric Administration. National Climate Data Center. [Online]. Available:

http://www.ncdc.noaa.gov/temp-and-precip/us-climate-regions.php

[22] USDA ${ }^{\text {a }}$. (2012). National Agricultural Statistics Service. Data and Statistics Quick Stats. [Online]. Available: http://www.nass.usda.gov/Quick_Stats/Lite/
[23] USDA ${ }^{\mathrm{b}}$. (2012). Economic Research Service. [Online]. Available: http://www.ers.usda.gov/data-products/commodity-costs-and-returns. aspx

[24] P. M. Raymond and B. Wolfgang, "Impacts of Present and Figure Climate Change and Climate Variability on Agriculture in the Temperature Regions: North America," Climate Change, vol. 70, pp. 137-164, May 2005.

[25] S. Wolfram and J.R. Michael, "Nonlinear temperature effects indicate severe damages to U.S. crop yields under climate change," in Proceedings of the National Academy of Sciences of the United States of America, vol. 106, pp. 15594-15598, August 2009.

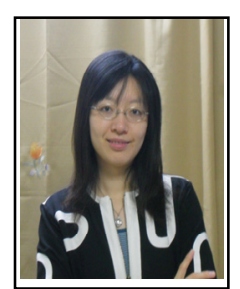

$\mathbf{X i a n g} \mathbf{L i}$ is an assistant professor at Tokyo Institute of Technology, Japan. She graduated from the University of British Columbia, Canada with the degree of bachelor (Bachelor of science for Natural Resources Conservation) in 2007. She received her science master degree in 2010 and Ph.D. degree in 2013 for International Environmental Economics at the University of Tokyo in Japan.

She was a DBA director at the Graduate School of International Corporate Strategy of Hitotsubashi University, a national University in Japan. She now works as an assistant professor at the Academy for Co-creative Education of Environment and Energy Science of Tokyo Institute of Technology, another national University in Japan.

Among Li's published refereed academic articles and issued patents, one that focused on climate change adaptation and mitigation strategy has been highlighted and introduced by Nature Climate Change Journal (Nature Publishing Group) (February, 2011)

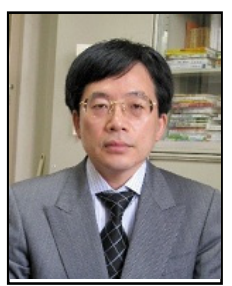

Nobuhiro Suzuki is a professor at the University of Tokyo in Japan. He graduated from the University of Tokyo in Japan with the degree of bachelor (Bachelor of Agricultural Economics) in 1982. He received his $\mathrm{Ph} . \mathrm{D}$. degree in Agricultural Economics from the University of Tokyo, Japan, in 1995.

He has experiences as a senior researcher and a director in National Research Institute of Agricultural economics (NRIAE), the Ministry of Agriculture in Japan, a director at JC research Institute in Japan, a professor at Kyushu University in Japan, and a visiting professor at Cornell University in the United States. He now works as a professor in the field of global environmental economics at the Graduate School of Agricultural and Life Sciences of the University of Tokyo.

Professor Suzuki has a great many published refereed papers and books in the field of policies and agricultural economics. 